03.1

\title{
Влияние угла наклона канала на конвективное смешение, вызванное неустойчивостью механического равновесия тройной газовой смеси при изотермической диффузии
}

\author{
(C) М.К. Асембаева ${ }^{1}$, В.Н. Косов ${ }^{1,2, \uparrow}$, С.А. Красиков ${ }^{1}$, О.В. Федоренко ${ }^{1}$ \\ ${ }^{1}$ Научно-исследовательский институт экспериментальной и теоретической фризики Казахского национального \\ университета им. аль-Фараби, Алматы, Казахстан \\ ${ }^{2}$ Казахский национальный педагогический университет им. Абая, Алматы, Казахстан \\ ฯ E-mail: kosov_vlad_nik@list.ru
}

Поступило в Редакцию 28 июня 2019 г.

В окончательной редакции 28 июня 2019г.

Принято к публикации 8 июля 2019г.

\begin{abstract}
Экспериментально изучены особенности конвективного режима, возникшего за счет неустойчивости механического равновесия тройной газовой смеси гелий-аргон-азот при изотермической диффузии. Рассматривается влияние угла наклона диффузионного канала на интенсивность конвективных течений. Проведены измерения интенсивности парциального переноса компонентов в наклонном канале при повышенных давлениях. Обнаружена нелинейная зависимость скорости смешения компонентов от угла наклона. Установлено, что наблюдаемый нетипичный для диффузии перенос компонентов возможен при определенном составе газовой смеси.
\end{abstract}

Ключевые слова: диффузия, конвекция, угол наклона, неустойчивость механического равновесия, газовая смесь.

DOI: 10.21883/PJTF.2019.21.48464.17952

Взаимодействие диффузионных и конвективных механизмов при межфазном тепломассопереносе реализуется в различных технологиях по ректификации и очистке газовых многокомпонентных смесей [1]. Интенсивность смешения во многом определяется как молекулярным, так и конвективным механизмом. Однако необходимо учитывать, что диффузия паров (газов) может привести к потере механического равновесия даже в неподвижных средах, что определяет возникновение концентрационной гравитационной конвекции, которая заметно меняет скорости смешения (испарения) компонентов системы [2,3] и влияет на прогнозируемый массоперенос. В опытах [2-6] по изучению изотермической диффузии в тройных смесях в вертикальных каналах были зарегистрированы синергетические эффекты, связанные со значительным увеличением парциальной скорости смешения в зависимости от давления и исходных составов исследуемых систем.

Целью настоящей работы является экспериментальное изучение многокомпонентного смешения в наклонном канале для тройных газовых смесей при различных давлениях и постоянной температуре.

Для решения поставленной задачи использовалась смесь гелий-аргон-азот. Опыты проводились на устройстве, изображенном на рис. 1, которое представляло собой модифицированный вариант двухколбового аппарата [7]. Диффузионная ячейка представляла собой две колбы приблизительно равного объема $\left(V_{u}=185 \cdot 10^{-6} \mathrm{~m}^{3}, V_{l}=186 \cdot 10^{-6} \mathrm{~m}^{3}\right)$, которые соединялись прямоугольным вертикальным каналом разме- ром $a \times b \times L=30 \times 6 \times 160 \mathrm{~mm}$ (рис. 1, $a$ ). Диффузионная ячейка была закреплена на устройстве наклона (рис. $1, b)$, что позволяло проводить опыты при различных углах по отношению к вертикальной оси в диапазоне $\alpha=0-90^{\circ}$. Температура во всех опытах была постоянной и равной $T=298.0 \mathrm{~K}$.

Методика проведения эксперимента предполагала следующие процедуры. Верхняя колба объемом $V_{u}$ заполнялась смесью гелия и аргона, нижняя колба объемом $V_{l}$ - соответственно азотом. После фиксации давления опыта и угла наклона с помощью специального устройства соединяющий колбы канал открывался. При этом регистрировалось время начала процесса смешения. По окончании опыта канал перекрывался и отмечалось время завершения смешения. Анализ газовых смесей из каждой колбы осуществлялся хроматографическим способом, особенностью которого являлось непосредственное измерение концентрации для аргона и азота. Концентрация для гелия могла быть получена из условия сохранения числа частиц

$$
\sum_{i=1}^{3} c_{i}=1,
$$

где $c_{i}-$ концентрация $i$-го компонента.

Опыт повторялся несколько раз и посредством усреднения определялось конкретное значение концентрации компонентов. Во всех экспериментах при любых составах и давлениях плотность смеси гелия и аргона в верхней колбе была меньше, чем плотность азота, который располагался в нижней колбе. 

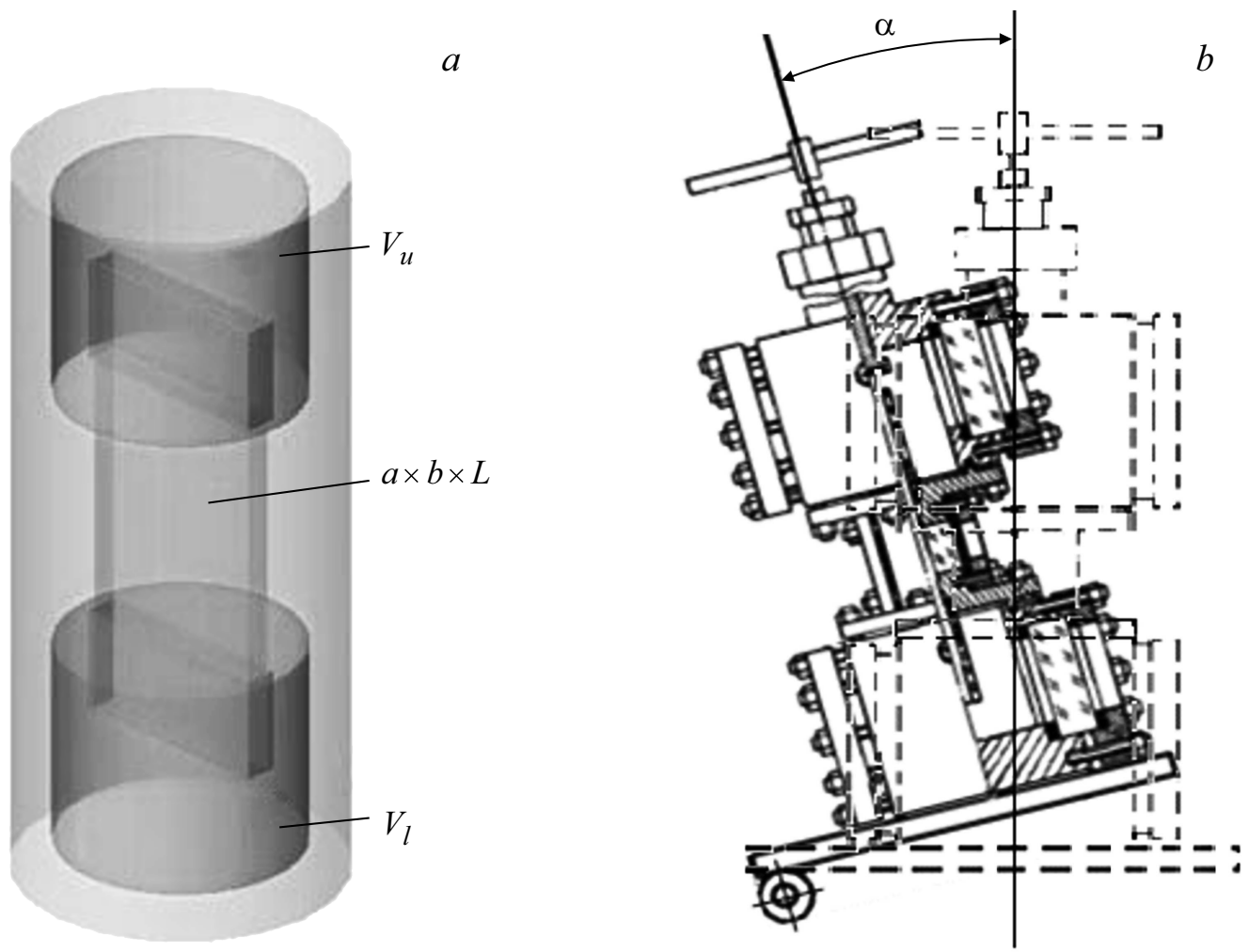

Рис. 1. Диффузионная ячейка двухколбового аппарата. $a-$ виртуальная 3D-модель двухколбового устройства, $b-$ двухколбовый аппарат при различных углах наклона.

На рис. 2 приведены концентрации переноса аргона и азота при различных давлениях для вертикальной ориентации канала. В системе $(0.43 \mathrm{He}+0.57 \mathrm{Ar})-\mathrm{N}_{2}$ (числа перед химическим элементом соответствуют исходному составу компонента в смеси) прослеживается нелинейная зависимость концентраций от давления (рис. 2,a). Наблюдается существенное расхождение между экспериментальными результатами и вычисленными в предположении диффузии. Вычисления для заданных условий опыта и геометрических характеристик канала осуществлялись с помощью расчетного модуля Flow Simulation пакета Solid Works [8]. При расчетах принимались во внимание процессы диффузии, смешения, искажения диффузионного фронта и перетекания более тяжелого газа в легкий в зависимости от угла наклона. Приведенные зависимости не типичны для диффузии, при которой наблюдается уменьшение интенсивности смешения с ростом давления. Не соответствует диффузионному представлению смешения и зарегистрированный максимум по интенсивности переноса аргона и азота. Его возникновение можно объяснить неустойчивостью механического равновесия смеси с последующим возникновением конвективных течений [6]. Уменьшение доли аргона в исходном составе смеси влияет на повышение устойчивости системы. При определенном составе в смеси
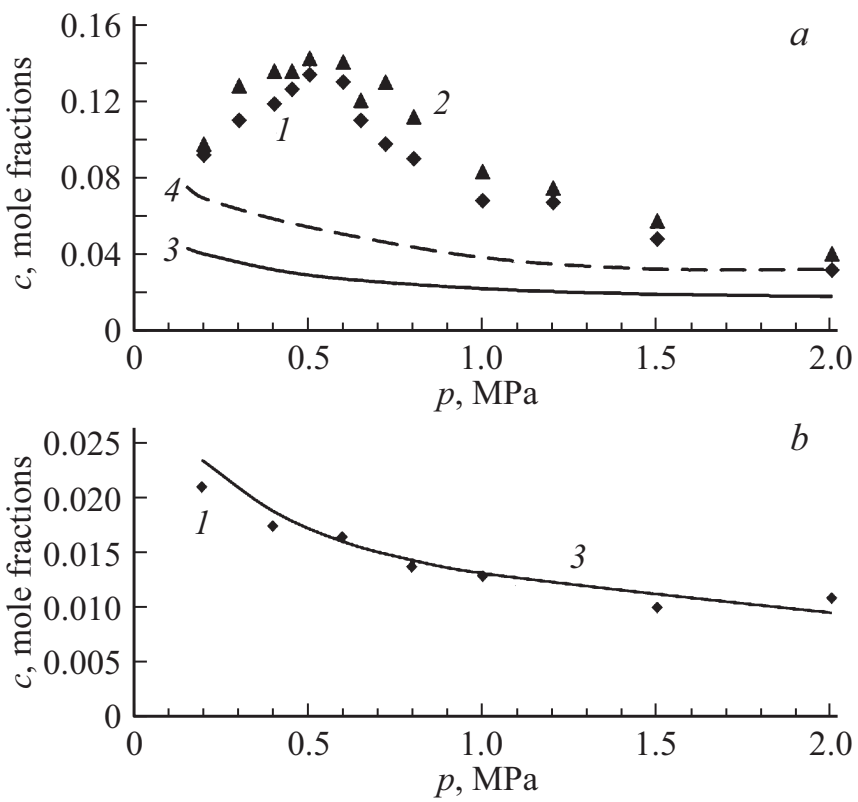

Рис. 2. Концентрации компонентов при различных давлениях в вертикальном плоском канале при $T=298.0 \mathrm{~K}$ для систем $(0.43 \mathrm{He}+0.57 \mathrm{Ar})-\mathrm{N}_{2}(a)$ и $(0.66 \mathrm{He}+0.34 \mathrm{Ar})-\mathrm{N}_{2}(b)$. Экспериментальные точки: 1 - аргон, 2 - азот. Сплошная (3) и штриховая (4) линии соответствуют вычисленным в предположении диффузии данным для аргона и азота. 

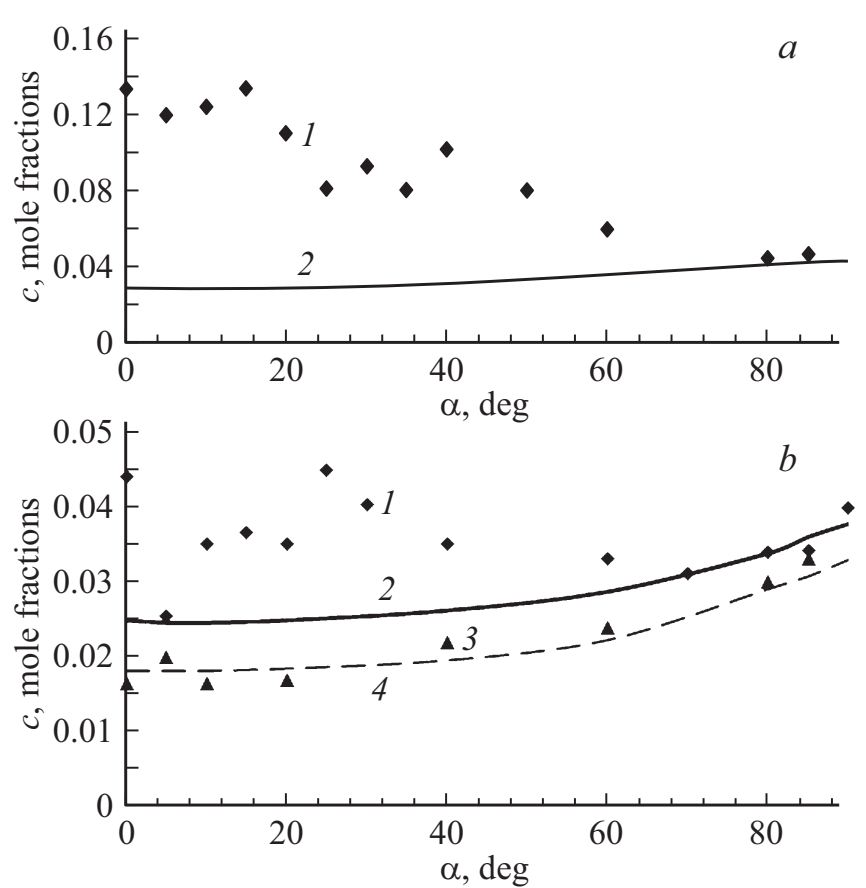

Рис. 3. Концентрации аргона для различных углов наклона диффузионного канала. $a-$ экспериментальные (1) и вычисленные в предположении диффузии (2) данные для системы $(0.43 \mathrm{He}+0.57 \mathrm{Ar})-\mathrm{N}_{2}$ при $p=0.34 \mathrm{MPa}$ и $T=298.0 \mathrm{~K}, b-$ экспериментальные $(1,3)$ и вычисленные в предположении диффузии $(2,4)$ данные для системы $(0.58 \mathrm{He}+0.42 \mathrm{Ar})-\mathrm{N}_{2}$ при $p=0.33 \mathrm{MPa}$ и $T=298.0 \mathrm{~K}(1,2)$ и для системы $(0.66 \mathrm{He}+0.34 \mathrm{Ar})-\mathrm{N}_{2}$ при $p=0.4 \mathrm{MPa}$ и $T=298.0 \mathrm{~K}(3,4)$.

реализуются только диффузионные механизмы переноса (рис. 2,b). Опытные данные в пределах погрешности эксперимента совпадают с вычисленными в предположении диффузии. Аналогичная картина наблюдается и для азота. Чтобы исключить перегруженность рисунков подобными зависимостями, здесь и далее концентрационные распределения по азоту приводиться не будут.

На рис. 3, а представлены концентрации аргона при различных углах наклона диффузионного канала и давлении $p=0.34 \mathrm{MPa}$. При максимальном содержании аргона в исследуемой смеси регистрируется сложный колебательный процесс (рис. 3, $a$ ). Экспериментальные данные значительно превышают вычисленные, что свидетельствует о наличии конвективных механизмов в суммарном массопереносе. Несмотря на общую тенденцию уменьшения интенсивности конвективного переноса при увеличении наклона диффузионного канала, при значениях угла $\alpha=15$ и $40^{\circ}$ отмечаются максимумы. При углах $\alpha \geqslant 45^{\circ}$ конвективная составляющая суммарного переноса начинает снижаться и при углах $\alpha \geqslant 80^{\circ}$ в системе наблюдается диффузия. В этом случае экспериментальные значения совпадают с вычисленными.
C уменьшением содержания аргона в смеси сложный характер массопереноса сохраняется (рис. 3,b). Однако интенсивность конвективных течений слабее, чем для предыдущего случая. На это указывают существенно меньшие расхождения между экспериментальными и вычисленными данными. При угле наклона $\alpha=25^{\circ}$ отмечается максимум переноса. Затем система релаксирует к устойчивому диффузионному состоянию, которое наступает при угле $\alpha \geqslant 70^{\circ}$. Наконец, можно подобрать такой исходный состав смеси: $(0.66 \mathrm{He}+0.34 \mathrm{Ar})-\mathrm{N}_{2}$, при котором для любых углов наклона будет иметь место диффузионное смешение. Совпадение экспериментальных и расчетных данных наблюдается при любых углах наклона диффузионного канала (рис. $3, b)$.

Таким образом, в наклонных каналах наблюдаются сложные конвективные режимы. При определенных углах наклона регистрируются нелинейные значения интенсивности переноса, которые не типичны для диффузии. Если в тройной смеси реализуется диффузионное смешение, то оно таковым и останется при любых углах наклона. Другим фактором, влияющим на возникновение сложных режимов смешения, является давление. Результаты эксперимента показывают, что угол наклона диффузионного канала и давление могут являться управляющими параметрами конвективного переноса, вызванного неустойчивостью механического равновесия изотермической тройной газовой смеси.

\section{Финансирование работы}

Работа поддержана грантом Комитета науки Министерства образования и науки Республики Казахстан в рамках проекта № АР05132427 „Реализация принципа конвективных сепараторов в наклонных каналах“.

\section{Конфликт интересов}

Авторы заявляют, что у них нет конфликта интересов.

\section{Список литературы}

[1] Incropera F.P., DeWitt D.P., Bergman T.L., Lavine A.S. Fundamentals of heat and mass transfer. 6th ed. Wiley, 2006. $999 \mathrm{p}$.

[2] Косов В.Н., Селезнев В.Д., Жаврин Ю.И. // ЖТФ. 1997. T. 67. B 10. C. 139-140.

[3] Дильман В.В., Липатов Д.А., Лотхов В.А., Каминский В.A. // Теорет. основы хим. технологии. 2005. Т. 39. № 6. С. 600-606.

[4] Смирнов А.Ю., Каширская О.А. // Успехи в химии и хим. технологии. 2008. Т. 22. № 3(83). С. 57-60.

[5] Жаврин Ю.И., Молдабекова М.С., Поярков И.В., Мукамеденкызы В. // Письма в ЖТФ. 2011. Т. 37. В. 15. С. 62-68. 
[6] Косов В.Н., Кульжанов Д.У., Жаврин Ю.И., Федоренко О.В. // ЖФХ. 2017. Т. 91. № 6. С. 931-936.

[7] Шашков А.Г., Золотухина А.Ф., Василенко А.Б. Фактор термодиффузии газовых смесей. Минск: Белорус. наука, 2007. 239 c

[8] Алямовский А.А., Собачкин А.А., Одинщов Е.В., Харитонович А.И., Пономарев Н.Б. Solid Works 2007/2008. Компьютерное моделирование в инженерной практике. СПб.: БХВ-Петербург, 2008. 1040 с. 